\section{The "new" mitochondrial disorders}

\section{A H V Schapira}

\section{The "new" mitochondrial disorders}

$\mathrm{t}$ is now clear that mitochondria serve two fundamental biological roles: the provision of ATP by aerobic respiration, and the mediation of cell death by apoptosis. Production of ATP is achieved primarily by oxidative phosphorylation and also through the tricarboxylic acid cycle and $\beta$-oxidation of fatty acids. The oxidative phosphorylation system comprises the respiratory chain and ATP synthase and consists of five multisubunit proteins, termed complexes I to $\mathrm{V}$ (table 1), embedded in the inner mitochondrial membrane. Electrons are passed down the chain and protons are pumped from the matrix side to the space between the inner and outer mitochondrial membranes. This creates an electrochemical gradient (membre tential) which is used to drive ATP production via ATPase (complex V). The production via ATPase (complex V). The
operation of the mitochondrial respiratory chain and oxidative phosphorylation (MITOX) system is responsible for the production of more than $95 \%$ of a cell's superoxide ions.

Mitochondria contain their own DNA, which is present in multiple copies. Human mitochondrial DNA (mtDNA) is a circular double stranded molecule 16493 bases long encoding two ribosomal RNAs (rRNA), 22 transfer RNAs (tRNA), and 13 proteins. These proteins are all part of the oxidative phosphorylation system. MtDNA remains dependent on the nucleus for the proteins that undertake and regulate its transcription, translation, replication, and repair. Indeed the nucleus encodes more than $98 \%$ of mitochondrial proteins, including 70 of the 83 proteins of complexes I to V.

The MtDNA encoded proteins are translated on mitochondrial ribosomes and incorporated directly into complexes I, III, IV, and V on the inner membrane. By contrast, nuclear encoded proteins are translated on cytosolic ribosomes and must be imported into the mitochondrion. This import system is highly complex and includes, for most proteins, targeting sequence at the $\mathrm{N}$-terminus that interacts with membrane receptors before being cleaved. ${ }^{1}$ The protein is ransported through the membrane and then folded and sorted to its correct intramitochondrial location.

There is now ample evidence that mitochondria play an important part in determining apoptotic cell death. ${ }^{2}$ Apoposis is important in embryological de-

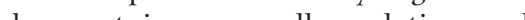
clopment ims everal other physiological functions. Numerous factors may induce apoptosis, many of which seem to act through mitochondria by opening of the megapore thereby decreasing the electrochemical gradient (permeability transition) and releasing apoptosis initiating factors. The megapore is located at inner/outer membrane junctions at (a) conpris including the peripheral benzodiazepine receptor, voltage dependent anion channel, and cyclophilin D. The pore is opened by proapoptotic molecules such as Bax and Bak, and by free radicals and respiratory chain defects, and is closed by antiapoptotic agents-for example BcLx and cyclosporine. The voltage dependent cyclosprine. The voltage dependent tant part in med effects of $\mathrm{BCL}_{2}$ proteins. Bax and Bak bind to the voltage dependent anion channel and accelerate opening of its channel, thereby allowing the release of cytochrome c. BcLx binds to and closes the voltage dependent anion channel, preventing cytochrome $c$ release ${ }^{3}$ Cytochrome $c$ is an integral part of the respiprespiitochondrial intermembranous space during the preapoptotic phase. Cytochrome c binds to Apaf- 1 and activates cascade, which in turn induces the changes that constitute the final events in apoptosis. The critical role of mitochondria in the pathway to apoptotic cell chontric pe the possible mechanisms that may be involved in the pathogenesis of mitochondrial diseases.

Numerous disorders have now been described in which mutations of mtDNA, or nuclear genes encoding respiratory chain subunits, have been identified. These have been the subjer These have been the subject of several recent reports and not be discussed further. This review focuses on a separate group of "new" mitochondrial diseases in which defective oxidative phosphorylation is due to mutations of nuclear genes that encode non-respiratory chain proteins that are involved in mitochondrial biogenesis and virectly or indirectly, cause defective directly or indirectly, cause defective mitochondrial energy metabolism and neurological disease.

\section{DEFECTS OF MITOCHONDRIAL}

\section{DNA BIOGENESIS}

Multiple delefions of mtDNA

Several families have been described with autosomal dominant or recessive inheritance of mitochondrial myopathy. The families with the dominantly inherited disorder usually have chronic progressive external ophthalmoplegia and proximal limb myopathy with ragged red fibres on biopsy, deficiency of oxidative phosphorylation on biochemical analysis, and multiple mtDNA deletions on Southern blotting. These delons ting. These secondary to a nuclear gene defect and contrast with the single deletions that characterise primary mitochondrial diseases such as the Kearns-Sayre syndrome. Abbreviations: MITOX, mitochondrial
oxidative phosphorylation system; mtDNA, mitochondrial DNA; rRNA, ribosomal RNA tRNA, transfer RNA; ANT-1, gene for the heart/skeletal muscle isoform of the adenine nucleotide translocator; MNGIE, mitochondrial neurogastrointestinal encephalomyopathy; GAA, guanine-adenine-adenine; YFHI, yeas frataxin homologue 1; CAG, cytosine-adenine guanine; SOD-1, superoxide dismulase 1; $\mathrm{OH}^{8} \mathrm{dG}$, 8-hydroxy-2-deoxyguanosine, IP-MRS, ${ }^{31}$ phosphorus magnetic resonance spectroscopy

\begin{tabular}{|llll|}
\hline Table 1 & The respiratory chain and oxidative & phosphorylation system \\
\hline Complex & Enzyme activity & $\begin{array}{l}\text { No of } \\
\text { subunits }\end{array}$ & $\begin{array}{l}\text { MtDNA encoded } \\
\text { subunits }\end{array}$ \\
\hline Complex I & NADH ubiquinone reductase & 41 & 7 \\
Complex II & Succinate ubiquinone reductase & 4 & - \\
Complex III & Ubiquinol cytochrome c reductase & 11 & 1 \\
Complex IV & Cytochrome c oxidase & 13 & 3 \\
Complex V & ATP synthase & 14 & 2 \\
\hline \multicolumn{5}{l}{} \\
\hline
\end{tabular}


There are at least three chromosomal loci for the autosomal dominant disorder (chromosomes 4, 10, and other(s)). ${ }^{12-14} \mathrm{~A}$ mutation on chromosome 3 was subsequently excluded on re-evaluation of the data available..$^{15}$ The mutation on chromosome 4 lies within the gene for the heart/ skeletal muscle isoform of the adenine nucleotide translocator (ANT-1), responsible for the exchange of ADP and ATP across the inner mitochondrial membrane. One type of autosomal reple mtDNA deletions-mitochondrial ple mtDNA deletions-mitochondrial
neurogastrointestinal encephalomyopathy (MNGIE) - has recently been linked to chromosome $22^{16}$ and found to be caused by a mutation of the thymidine phosphorylase gene. ${ }^{17}$ Patients with MNGIE typically present with chronic progressive external ophthalmoplegia, sensorimotor peripheral neuropathy, recurrent nausea, vomiting, and diarrhoea. A leukodystrophy may be seen on MRI. Thymidine phosphorylase activity is severely decreased and blood thymidine concentrations are high.

\section{Depletion of mtDNA}

Many patients with depletion of mtDNA present in the first few days or weeks of life with hypotonia and lactic acidosis or progressive hepatorenal failure. ${ }^{18}{ }^{19}$ Most die before the age of 12 months, although occasional less severely affected infants have been reported. In affected tissues, the concentrations of mtDNA are usually less than $30 \%$ but can be as low as less than $1 \%$ of age matched normal subjects. In some cases, the depletion is expressed in culture, ${ }^{20} 21$ the mtDNA depleted cells being capable of growing and dividing in specially supplemented medium. Genomic transplantation studies have shown that the mtDNA remaining in these patients' cells can br an be restored to normal by replacement of the nucleus with the nucleus from a normal cell, indicating that mtDNA depletion in these patients is caused by a nuclear gene defect.

\section{DISEASES DUE TO NUCLEAR \\ GENE MUTATIONS IN} NON-MITOX MITOCHONDRIAL

\section{PROTEINS}

Friedreich's ataxia is an autosomal recesdisorder with an incidence of 1 in 30000 to 50000 live births. The disorder usually becomes evident in childhood or adolescence, with ataxia, skeletal deformities, hyporeflexia, pyramidal tract deficits, and a hypertrophic cardiomyopathy. Most patients become wheelchair bound 10 to 15 years after diagnosis and die 5 to 10 years later from progressive cardiac failure. In $98 \%$ of progressive cardiac failure. In $98 \%$ of an expanded guanine-adenine-adenine
(GAA) repeat in intron 1 of the gene on chromosome 9 which encodes frataxin and results in an abnormality of RNA processing ${ }^{22}$ Frataxin is a widely expressed $18 \mathrm{kDa}$ protein of unknowr pressed ${ }^{23}$ kDa protein of unknown as close homology to a yeast gene (now termed yeast frataxin homologue $\mathrm{l}, \mathrm{YFHl}$ ) which when deleted results in defective energy metabolism, intramitochondrial iron accumulation, induction of the high affinity iron transport system, and low mtDNA concentrations. ${ }^{24}$ Frataxin was subsequently found to have a mitochenting chondrial targeting sequence and to be a mitochondrial protein. Mitochondrial unction studies have disclosed severe deficiencies in the activities of complexes I, II, and III, and aconitase in cardiac and skeletal muscle. ${ }^{26}{ }^{27}$ Furthermore, there is histological evidence for iron accumulation in these tissues. Thus, there is a striking these tissues. Thus, there is a striking parallel between the yeast nnockout model and the human disease. of particular interest is the demonstration in vivo in patients with Friedreich's ataxia of a defect of oxidative phosphorylation in skeletal muscle by ${ }^{31} \mathrm{P}$ magnetic resonance spectroscopy ( $\left.{ }^{31} \mathrm{P}-\mathrm{MRS}\right)$ correlating with the length of the patient's GAA repeat. ${ }^{28}$

Complexes I, II, and III and aconitase are all iron-sulphur containing enzymes, and their combined deficiency in Friedreich's ataxia, coupled with tissue iron accumulation, suggests that frataxin deficiency may result in a defect of ironsulphur protein construction. Iron is a pro-oxidant, and the pattern of enzyme defect in patients with Friedreich's patients with Friedreich's taxia is identical to that seen in the manganese superoxide dismutase stress ${ }^{29}$ supporting an important role for ree radicals in the pathogenesis of Friedreich's ataxia. This raises the possibility that effective antioxidants may have a disease modifying role in this neurodedisease modifying

Two recent studies have shown objective improvement in patients with Friedreich's ataxia given antioxidants. In one, 10 patients took high dose ubiquinone (coenzyme $\mathrm{Q}_{10}$ ) and vitamin $\mathrm{E}$ and significant improvements in their skeletal and cardiac muscle biochemical defects, as determined by ${ }^{31} \mathrm{P}-\mathrm{MRS}$, were ceted 3 and 6 months 30 and 24 mons R Lodi et al, unpublished resul ( $R$ Lodi et al, unpublished results). In another study, three patients were given debenone with improvements in cardiac hypertrophy over 3 to 6 months. ${ }^{31}$ Whether antioxidant therapy in Friedreich's ataxia will modify the course of the neurological dysfunction is not yet known, but this issue is currently the known, but this issue is curre
subject of a long term study,

\section{leigh syndrome}

Leigh syndrome usually presents in infancy or childhood with failure to thrive, hypotonia, recurrent vomiting, lactic acidosis, psychomotor retardation and evidence of brain stem or basal ganglia dysfunction. Magnetic resonance spectroscopy shows bilateral and symmetric

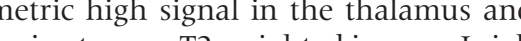
brain stem on T2 weighted images. Leigh syndrome is heterogeneous at the biochemical and molecular levels; defects of pyruvate dehydrogenase and respiratory chain complexes have been described, and mutations have been identified in pyruvate dehydrogenase or mtDNA gyres in some patients.

Interest has recently focused on a group of patients with Leigh syndrome with non-maternally inherited cytochrome oxidase (complex IV) deficiency. Somatic cell genetics demonstrated the nuclear basis of complex IV deficient Leigh syndrome, ${ }^{32}$ and mutations in the SURF-l gene were subsequently identified in a high propequently identiped in 3334 huRF-1 is antion of these patients." surf-l is a nuclear encoded mitochondrial protein involved in the maintenance of complex IV activity and mitochondrial respiration in yeast ${ }^{35}$ and is probably important in holoenzyme assembly. SURF-1 mutations in complex IV-deficient Leigh syndrome result in a severe decrease in enzyme activity ${ }^{36}$ severe decrease in enzyme activity. nuclear encoded genes encoding proteins involved in COX assembly have been identified including SCOI, SCO2 ${ }^{37}{ }^{38}$ and COX $10 .^{39}$ These mutations were associated with infantile onset of features that included hepatic failure, cardiomyopathy and lactic acido-

\section{Hereditary spastic paraplegia}

Hereditary spastic paraplegia results in the gradual onset and slow progression of leg spasticity, and sometimes also a distal predominantly sensory neuropathy, mental retardation, retinitis, optic atrophy, and amyotrophy. Prevalence is estimated at 1 in 10000 Autosomal dominant, recessive, and $X$ linked forms have been described. A new locus on 16q24.3 has recently been described with a $9.5 \mathrm{~kb}$ deletion and family and different frameshift mutations in a further two families. ${ }^{40}$ The gene product, paraplegin, has significant sequence homology to a class of yeast metalloproteases. ${ }^{41}$ Paraplegin was found to carry a mitochondrial $\mathrm{N}$-terminal targeting sequence, the mature protein colocalising with and being internalised cy, mitochondra. Muscle biopsies frem sies from two patients with hereditary spastic paraplegia and paraplegin deficiency showed several ragged red, succinate dehydrogenase positive, complex IV negative fibres. Biopsies from a further two less severely affected patients had occasional ragged red fibres only. The in the muscle of patients with hereditary spas- 
of a nuclear gene mutation causing apparently widespread mitochondrial abnormalities.

Dystonia

Movement disorders, and dystonia in particular, are known to occur more often than expected in patients with primary mitochondrial diseases. ${ }^{42}$ Several families with maternally inherited Leber's hereditary optic neuropathy with er's hereditary optic neuropathy with
dystonia and mutations in mtDNA genes encoding complex I subunits have been described. ${ }^{43-45}$ A specific and reproducible deficiency of complex I activity in patients with sporadic focal dystonia ${ }^{46}{ }^{47}$ has been identified, but not in patients with generalised dystonia linked or not to the dystonia-l gene. ${ }^{48}$

A nuclear encoded mitochondrial protein defect has now been identified in one particular type of dystonia. Deafness dystonia (Mohr-Tranebjaerg) syndrome is an $\mathrm{X}$ linked disorder characterised by progressive sensorineural deafness, cortical blindness, dystonia, dysphagia, and paranoia. ${ }^{49}$ Deafness dystonia syndrome is due to deletion or truncation of a gene (DFN-1) encoding a $11 \mathrm{kDa}$ protein termed DDPI. This protein has recently been identified, through homology studies, as a component of the mitochondrial import system. ${ }^{50}$ It is not yet known which proteins are affected by this import defect, nor whether oxidative phosphorylation is compromisedalthough the clinical phenotype is reminiscent of other mitochondrial encephalopathies.

\section{DISEASES DUE TO NUCLEAR \\ GENE DEFECTS IN \\ NON-MITOCHONDRIAL \\ PROTEINS}

\section{Huntington's diseas}

Huntington's disease is an autosomal dominant neurodegenerative disorder characterised clinically by chorea, ataxia, and dementia and pathologically by the loss of neurons of the striatum containing $\gamma$-aminobutyric acid and enkephalin. It usually presents in early to middle adult life, although both juvenile and late onset forms are recognised. The mutation responsible is an abnormally expanded (>36) cytosine-adenineguanine (CAG) repeat in the huntingtin gene on chromosome 4. Knockout of the huntingtin gene results in early fetal death in mice, death in mice, implying a critical role in embryogenesis. ${ }^{51}$ The gene product, huntingtin, is a widely expressed 349 kDa protein of unknown function. ${ }^{52}$ Cultured cells expressing mutant huntingtin molecules have intranuclear inclusions,,$^{53}$ which are also seen in the brains of patients with Huntington's disease $^{54}$ and in Huntington transgenic mice.

Excitotoxicity has been suggested to play an important part in neuronal cell death in Huntington's disease. ${ }^{56}$ This is dependent on glutamate excitation of $\mathrm{N}$-methyl-D-aspartate receptors, inward flow of calcium, activation of nitric oxide synthase, and nitric oxide generation. Nitric oxide, and particularly peroxynitrite, the product of the reaction of nitric oxide with superoxide $\mathrm{O}_{2}^{-}$are free radicals that can damage tissues. An important factor in this sequence is the release of the energy dependent magnesium blockade of NMDA receptors, thus rendering ambient concentrations of glutamate excitotoxic. Evidence for a defect of energy metabolism in Huntingext on's disease arises from various sources, ncluding reduced striatal and cerebral cortical glucose utilisation as detected by positron emission tomography and increased lactic acid concentrations as detected by magnetic resonance sect a analyses by several groups have shown (a) shown a evere MITOX defect: deficiency of complexes II and III and IV $V^{60}{ }^{61}$ in addition to a $90 \%$ decrease in aconitase activity. ${ }^{62}$ R6/2 HD transgenic mice also show evidence of striatal deficiencies of complex IV and aconitase. ${ }^{63}$

The mitochondrion plays a central part in cell biology in maintaining life through ATP generation and in determining cell death through its role in apoptosis.

The development of such severe defects of mitochondrial respiratory chain fects of mitochondrial respiratory chain and aconitase function must be secondary to the primary huntingtin gene defect. The question arises as to whether this is a causal relation or the consequence of alternative biochemical and pharmacological events. Huntingtin is expressed in muscle and, at a low level, in fibroblasts and lymphoblasts. Mitochondrial respiratory chain and aconitase activities were normal in fibroblasts and platelets from patients with Huntington's disease. ${ }^{60}$ Magnetic resonance spectroscopy in muscle of patients with Huntington's disease has been reported to be abnormal ${ }^{58}$ This finding has recently been confirmed and also decreased rates of ATP synthesis (which correlated with the length of the CAG repeat - that is, the longer the repeat, the worse the defect) were found in the muscle of both symptomatic and presymptomatic patients.

The presence of mitochondrial defects in Huntington's disease brain and skeltal muscle, in particular the correlation f the latter wiht the lengh of the CAG repeats, suggests that mutant huntingtin may have a direct role in inducing mitochondrial abnormalities. These finding are supported by the protective effects of creatine in the R6/2 transgenic mouse een the basis for a trial in the United States of ubiquinone therapy in Huntington's disease.

\section{Wilson's disease}

Wilson's disease is an autosomal recessive disorder which results in liver disease in $40 \%$ of affected patients, neurological dysfunction (dystonia, rigidity, parkinsonism) in $40 \%$, and psygidity, parkinsonism in (d0\%, and psychiatric disease in $20 \%$ of patients. The Wilson's disease gene on 13q14.3 codes for a protein that functions as a P-type ATPase localised in both the Golgi network $^{66}$ and possibly in mitochondria. ${ }^{67}$ We have recently identified severe defects of MITOX function, aconitase deficiency in liver samples rom patients with Wilson's disease. This pattern of enzyme defect, identical to that seen in Friedreich's ataxia and to that found in the superoxide dismutase 2 knockout mouse, ${ }^{29}$ suggests that free radical formation and oxidative damage may contribute to the pathogenesis disease. This might be expected as copper, which accumulates in the liver in Wilson's disease, may substitute for iron in free radical generating reactions. The results suggest that effective antioxidant therapy may be helpful in patients withWilson's disease.

\section{DISEASES WITH UNDEFINED MITOCHONDRIAL CONTRIBUTION TO AETIOLOGY AND PATHOGENESIS}

There are a group of neurodegenerative diseases where there is clear evidence of mitochondrial dysfunction. However, the role of mitochondria in aetiology and pathogenesis as yet remains undefined-and may be primary or secondary. Indeed it is increasingly likely that in Parkinson's disease in particular the mitochondrial abnormality may be primary in some patients, secondary in others, but still plays an important contributory part in pathogenesis in many. The position with respect to Alzheimer's disease and motor neuron disease is less clear.

\section{Parkinson's disease}

The cause of dopaminergic cell death in Parkinson's disease is not known. However, during the past 2 years several mutations have been identified in both autosomal dominant and recessive Parkinson's disease. ${ }^{69-72}$ Environmental agents-for example, 1-methyl-4-phenyl 1,2,3,6 tetrahydropyridine, manganese, and carbon monoxide- have also been associated with the development o associated with the development of par- 
has been produced by parentral infusion of rotenone-a naturally occurring pesticide and complex I inhibitor. ${ }^{73}$ It seem increasingly likely that idiopathic, sporadic Parkinson's disease may be the clinical, pathological, and possibly bioclinical, pathological, and possibly bio-
chemical end point common to various chemical end point commo
different aetiological agents.

different aetiological agents.
There is evidence of a mitochondrial complex I defect in the substantia nigra of patients with Parkinson's disease (see Schapira et $a l^{74}$ for review), and this defect is also detectable in platelets in some patients with sporadic Parkinson's disease. ${ }^{75}$ Genomic transplantation studies have demonstrated that the complex I defect in this subgroup is determined by mtDNA. ${ }^{767}$ Whether this defect is caused by mtDNA mutations or a series of polymorphisms that render cells susceptible to damage by, for instance, an environmental agent, is not yet known, nor whether such mtDNA abnormalities are somatic or inherited. Any mtDNA mutation may be systemically distributed but, as with primary mtDNA mutations, may be heteroplasmic (present in varying proportions of wild-type and mutant genomes) and therefore, for instance, be present in higher concentration in certain tissues-for example, the substantia nigra. In addition, the biochemical (oxidative stress, increased iron) and pharmacological (dopamine oxidation, excitotoxicity) characteristics of the substantia nigra may exacerbate the complex I defect. Some or all of these processes may influence complex I function and respiratory (proton pumping) activity such as to decrease membrane potential, thereby lowering the cell's threshold to undergo apoptosis. These events and their effects may vary from one cell type to another, and could particularly affect neurons in view of their dependence on oxidative phosphorylation. These findings suggest that, in some patients with Parkinson's disease, mtDNA defects may be primary, whereas in others the mitochondrial abnormalities may be secondary to, for instance, free radical generation or possibly exog enous toxins.

\section{Alzheimer's disease}

Evidence for mitochondrial dysfunction in Alzheimer's disease is derived from several different but complementary studies. A specific deficiency in the activity of complex IV (cytochrome oxidase) has been described in Alzheimer's dishase brain $n^{78-80}$ and in platelet ease brain ${ }^{78-80}$ and in platelet
mitochondria. ${ }^{81}$ A decrease in the expression of nuclear and mtDNA encoded COX subunits has been found in Alzheimer's disease brain. ${ }^{82}$ The complex IV defect may be transferred to recipient cells using mtDNA derived from patients with Alzheimer's disease, ${ }^{83}$ implying that with Alzheimer's disease, implying that complex IV deficiency. Indeed a group of
mtDNA "mutations" were identified, but subsequently found to be amplifications of nuclear pseudogenes. ${ }^{84}{ }^{85}$ Down regulation of COX gene expression is known to occur in association with decreased courity or ${ }^{8}$ Complex IV deficiency has also been Complex IV defiency has also reported in Friedreich's ataxia and spinocerebellar ataxia- 1 brains ${ }^{87}$ and so is not specific to Alzheimer's diseaseunlike the complex I deficiency in Parkinson's disease. At present, therefore, there remains uncertainly about the relevance of complex IV deficiency in Alzheimer's disease and whether it may represent a primary phenomenon in some, or a secondary epiphenomenon in all.

\section{Motor neuron disease}

The evidence for mitochondrial dysfunction in motor neuron disease (amyotrophic lateral sclerosis) is compelling and fits well with our current understanding of the pathogenesis of this disorder. Mutations in the gene for superoxide dismutase 1 (SOD-1) are found in about $20 \%$ of patients with familial forms of motor neuron disease ${ }^{88}$ and may induce neuronal damage by anhay pen enhanced peroxidation. There have been several reports of free radical induced damage to proteins, lipid, and DNA in postmortem tissue from patients with motor neuron disease. .0-95 $^{9-9}$ Increased concentrations of 8-hydroxy-2-deoxyguanosine

$\left(\mathrm{OH}^{8} \mathrm{dG}\right)$ - an indicator of oxidatively damaged DNA-have also been found in plasma, urine, and CSF from patients with motor neuron disease, and to with ere and to increase with progression of the both sporadic and familial forms of the disease, as well as in a transgenic mouse model with a SOD-1 mutation (G93A). ${ }^{97}$ Furthermore, fibroblasts from patients with sporadic and familial motor neuron disease are more susceptible to damage by free radicals ${ }^{98}$ Increased activities of respiratory chain complexes I-III were respiratory chain complexes I-III were seen in postmortem brain tissue from amilial but not sporadic patients. Complex I activity was increased in the forebrain of the G93A transgenic SOD-1 mouse model but complex I and IV activities were decreased in the spinal cord. ${ }^{99}$ Complex I activity has been found to be decreased in skeletal muscle from patients with motor neuron disease ${ }^{100}$ passecter with with the presence of mtDNA deletions ${ }^{10}$ which in turn were correlated with negative staining for complex IV in single fibres. ${ }^{102}$ Mitochondrial morphological changes have been found in anterior horn cells from patients ${ }^{103}$ and the G37R transgenic mouse model. ${ }^{104}{ }^{105}$ Complex IV was decreased in motor neuron disease motor neurons 106 and an excen " and an te common" mtDNA eletion was found in motor neuron disease motor cortex. ${ }^{107}$
The mitochondrial abnormalities in motor neuron disease are most easily explained as a secondary phenomenon to free radical mediated damage. The pattern of respiratory chain deficiency is consistentwithexcitotoxicityand peroxynitrite mediated protein and peroxyThis is supportion This is supported by evidence for increased free nitrotyrosine in patients ${ }^{10}$ and a transgenic mouse model with a SOD-1 mutation. ${ }^{109}$ Whether the mitochondrial dysfunction is merely an epiphenomenon, or whether it also contributes to disease pathogenesis, is not clear. However, the recent demonstration that creatine significantly prolongs life in a SOD-1 transgenic model suggests that SOD-1 transgenic model suggests that improving mitochondrial function may be of benefit to patients with motor neuron disease. ${ }^{110}$ This may be achieved for instance with either carnitine or ubiquinone-or both-and could be used in conjunction with other potentially disease modifying therapies including NMDA antagonists. A double blind placebo controlled trial to address these issues is currently being initiated.

\section{CONCLUSIONS}

The mitochondrion plays a central part in cell biology in maintaining life through ATP generation and in determining cell death through its role in apoptosis. It is hardly surprising, therefore, that mitochondrial dysfunction, both primary and secondary is associated with disease. The dependence of whe of nervous tissue, in particular, on intac mitochondrial activity means tha neurological dysfunction will be a frequent consequence of both primary and secondary respiratory chain defects. Evidence is emerging that there may be common pathogenetic features in several of the neurodegenerative diseases. These may include defects of intracellular promay include defects of intracellular protein handing, protein danage with consequent aggregation and accumulation, and mitochondrial dysfunction. The de velopment of therapeutic strategies to intervene in the cascade of events that involves these processes and terminates in cell death may provide disease modifying drugs not only for neurodegenerative disorders, but also for the primary mitochondrial defects.

\section{J Neurol Neurosurg Psychiatry
2002;72:144-149}

\section{Author's affiliation}

A H V Schapira, University Department of

Clinical Neurosciences, Royal Free and

University College Medical School, and Institute of Neurology, University College London,

Correspondence to: A H V Schapira;

\section{REFERENCES}

Haucke $\mathbf{V}$, Schatz $\mathrm{G}$. Import of proteins into
mitochondria and chloroplasts. Trends Cell milochondria and ch 
2 Susin SA, Zamzami N, Kroemer G. Mitochondria as regulators of apoptosis: doubt no more. Bioch

3 Shimizu, S, Narita M Tsuijmoto Y, Bcl-2 family proteins regulate the release of apoptogenic cytochrome $c$ by the
mitochondrial channel VDAC. Nature

4 Schapira AHV, ed. Mitochondrial disorders. J

DiMauro S Bonilla E Davidson M. Mitochondria in neuromuscular disorders.
Biochim Biophys Acta 1998;1366:199-210. Wallace DC. Mitochondrial diseases in man and mouse. Science 1999,283:1 482-8. respiratory chain disorders 1 : mitochondrial DNA defects. Lancet 2000:355:299-304. 8 Leonard JV, Schapira AHV. Mitochondrial respiratory chain disorders 1 :

Neurodegenerative disorders and nuclear

gene defecls. Lancel 200,355:389-94. first nuclear-encoded complex I mutation in patient with Leigh syndrome. Am J Hum Gen 1998;63:1598-608.

10 Triepels RH, van den Heuvel LP, Loeffen JLCM, et al. Leigh syndrome associated with (C) encoded subunit of

11 Schuelke M Smeitink J, Mariman E, et al. Mutant NDUFV1 subunit of mitochondrial complex I causes leukodystrophy and myoclonic epilepsy.

12 Suomalainen JM, Kaukonen J, Amati P, et al. An autosomal locus predisposing to 1995;9:146-51.

13 Kaukonen JA, Amati P, Suomalainen A, et al. An autosomal locus predisposing to multiple deletions of m+DNA on chromoso
3p. Am J Hum Genet 1996:58:763-9.

Kaukonen J Zeviani M Comi GP, et al.A third locus predisposing to multiple deletions third locus predisposing to multiple deletions
of m+DNA in autosomal dominant progressive external ophthalmoplegia. Am J Hum Genet

15 Kaukonen J, Juselius JK, Tiranti V, et al. Role of adenine nucleotide translocator 1 in 2000;289:782-5.

16 Hirano M, Garcia-de-Yebenes J, Jones AC, et al. Mitochondrial neurogastrointestinal encephalomyopathy syndrome maps to
chromosome 22q13.32-qter. Am J Hum Genet chromosome 22q13.32-qter. Am J Hom
1998;63:526-33.

17 Nishino I, Spinazzola A, Hirano M. Thymidine phosphorylase gene mutations in Science 1999;283:689-92.

18 Tritschler HJ, Andreetta F, Moraes CT, et al. Mitochondrial myopathy of childhood onse associated with depletion of mitoch
DNA. Neurology 1992:42:209-17.

19 Morris AAM, Taanman JW, Blake $J$, et al. Leigh syndrome associated with liver failure and $\mathrm{mtDNA}$ deple

20 Taanman J-W, Bodnar AG, Cooper JM, et al. Molecular mechanisms in mitochondrial 1997;6:935-42

21 Bodnar AG, Cooper JM, Holt I, et al. Nuclear complementation restores mtDNA levels in cultured cells from a patient with mtDNA depletion.

22 Campuzano V Montermini L, Molto MD. Friedreich's ataxia: autosomal recessive disease caused by an intronic GAA triple repeat expansion. Sci
1996;217:1423-7.

23 Campuzano V, Montermini L, Lutz $Y$, et al. patients and is associated with mitochondria membranes. Hum Mol Genet 1997;6:1771-80. 24 Wilson RB, Roof DM. Respiratory deficiency
due to loss of mitochondrial DNA in yeast lacking the frataxin homologue. Nat Genet 25 Koutnikova H, Campuzano V, Foury F, et al. Koutnikova $\mathrm{H}$, Campuzano V, Foury $\mathrm{F}$, et al.
Studies of human, mouse and yeast homologues indicate a mitochondrial function for frataxin. Nat Genet 1997;16:345-51.

26 Rötig A, De Lonlay P, Chretien D, et al. Aconitase and mitochondrial iron-sulphur
protein deficiency in Friedreich ataxia. Nat protein deficiency in Frie
Genet 1997:17.215-17.

27 Bradley JL, Blake J, Chamberlain S, et al. Mitochondria alterations in Friedreich's ataxia: comparison with the yeast genetic

model. J Neurol 1998;24S:408.
Lodi R, Cooper JM, Manners D, et al. Deficit 28 Lodi $R$, Cooper JM, Manners D, et al. Defici
of mitochondrial respiration in patients with
Friedreich's ataxia shown by in vivo $31 \mathrm{P}$ magnetic resonance spectroscopy. Proc Natl Acad Sci USA 1999;96: $11492-5$.
Melov S Coskun P, Patel M, et al.

29 Melov $S$, Coskun $P$, Patel $M$, et al. Mitochondrial disease in superoxide USA 1999:96:846-51.

30 Lodi R, Hart PE, Rajagopalan B, et al. Antioxidant treatment improves in vivo cardiac and skeletal muscle bioenergetics in patients 2001;49:590-6.

31 Rustin $\mathrm{P}$, von Kleist-Retzow JC, Chantrel-Groussard $K$, et al. Effect of idebenone on cardiomyopathy in Friedreich's ataxia: a preliminary study. Lance

1999;354:477-9.

32 Tiranti V, Munaro M, Sandona $D$, et al. Nuclear DNA origin of cytochrome c oxidas evidence based on patient's: genived rho transformants. Hum Mol Genet 1995;4:2017-23.

33 Tiranti V, Hoertnagel K, Carrozzo R, et al. Mutations of SURF-1 in Leigh disease associated with cytochrome
deficiency. Am $J$ Hum Genet
1998:63:1609-21

4 Zhu ZQ, Yao JB, Johns T, et al. SURF I encoding a factor involved in the biogenesis
of cytochrome $c$ oxidase, is mutated in leigh of cytochrome c oxidase, is mutated in Leigh
syndrome. Nat Genet 1998:20:337-43.

35 Mashkevich G, Repetto B, Glerum DM, et al. SHY Y, the yeast homolog of the mammalian SURF-1 gene encodes a mitochondrial protein required for respiration. I Biol Chem

36 Tiranti V, Jaksch $M$, Hofmann $S$, et al.
Loss-of-function mutations of SURF- 1 are specifically associated with Leigh syndrome with cytochrome c oxidase deficiency. Ann Neurol 1999;46:161-6.

37 Valnot I, Osmond S, Gigarel N, et al. Mutations of the SCOI gene in mitochondria cytochrome c oxidase deficiency w 2000; 67: 1104-9.

38 Papadopoulou LC, Sue CM, Davidson MM et al. Fatal infantile cardioencephalomyopathy a COX assembly

39 Valnot I, von Kleist-Retzow JC, mutation in the human heme. A: farnesyltransferase gene (Cox 10) causes
cytochrome c oxidase deficiency. Hum Mol

40 De Michele G, De Fusco M, Cavalcanti F, et al. A new locus for autosomal recessive hereditary spastic paraplegia. Am J Hum

1 Casari G, De Fusco M, Ciarmaton S, et al. Spastic paraplegia and oxidative phosphorylation impairment caused by nuclear-encod 1998;93:973-83

42 Truong DD, Harding AE, Scaravilli F, et al. Movement disorders in mitochondrial myopathies: a report of nine cases with two

43 Howell N, Kubacka I, Xu M, et al. Leber hereditary optic neuropathy: involvement of
the mitochondrial NDI gene and evidence for
an intragenic suppressor mutation. Am J Hum an intragenic suppressor mutation. Am J Hum
44 Jun AS, Brown MD, Wallace DC. A mitochondrial DNA mutation at nucleotide terite inherited leber hereditary optic neuropathy and dystonia. Proc Natl Acad Sci USA

1994;91:6202-10.
45 De Vries DD, Went LN, Bruyn GW, et al. Genetic and biochemical impairment of with Leber hereditary optic neuropathy and hereditary spastic dystonia. Am J Hum Genet hereditary spastic
1996;58:703-11.

46 Benecke R, Strümper P, Weiss H. Electron Iransfer complex I defect in idiopathic

47 Schapira AHV Warner T Gash MT, et al.

Complex I function in familial and sporadic

dystonia. Ann Neurol 1997;41:556-9.

48 Tabrizi SJ, Cooper JM, Schapira AHV. Mitochondrial DNA in focal dystonia: 0 cybrid analysis. Ann Neurd

49 Tranebiarg $\mathrm{L}$ Schwartz $\mathrm{C}$, Eriksen $\mathrm{H}$ et al A new $X$ linked recessive deafness syndrome with blindness, dystonia, fractures, and menta deficiency is linked to Xq22. J Med Genet 1995; 32:257-63.

50 Koehler CM, Leuenberger D, Merchant S, et mitochondrial disease. Proc Natl Acad Sci USA 1999;96:2141-6.

51 Zeitlin S, Liu JP, Chapman DL, et al. ncreased apoptosis and early embryonic ethality in mice nullizygous for the Untington's disease gene homolog. N

Genet 1995; 11:155-63.

Polyglutamine expansionin $G$, et al. pitope in Huntington's disease and four dominant cerebellar ataxias. Nature 1995;378:403-6.

53 Martindale D, Hackam A, Wieczorek A, et al. Length of huntingtin and its polyglutamine intracellular aggregates. Nat Genet

54 Roos RACC, Bots GTAM. Nuclear membrane indentations in Huntington's chorea. I Neurol

55 Davies SW, Turmaine $M$, Cozens BA, et al. Formation of neuronal intranuclear inclusions transgenic for the HD mutation. Cell
1997:90:537-48. 1997;90:537-48.

56 Beal MF. Does impairment of energy metabolism resulf in excitotoxic neuronal death in neurodegenerafive il nesses? A 57 Kuwert T, Lange HW, Langer K-J, et al.
Cortical and subcortical glucose consumption measured by PET in patients with Huntington's disease. Brain 1990;113: 1405-23.

8 Koroshetz WJ, Jenkins BG, Rosen BR, et al. disease and effects of coenzyme $Q$. Neurol 1997:41:160-5.

59 Hoang TQ, Dubowitz DJ, Moats $R$, et al Quantitative proton-decoupled P-31 MRS and H-1 MRS in the evaluation of Huntington's and Parkinson's disease. Neurology

60 Gu M, Cooper JM, Gash M, et al.

Mitochondrial defect in Huntington's disease caudate nucleus. Ann Neurol

61 Browne SE, Bowling AC, MacGarvey U, et al. Oxidative damage and metabolic ysfunction in Huntington's disease: selective vulnerability of the
1997; 41:646-53.

62 Tabrizi SJ, Cleeter M, Xuereb J, et al. Biochemical abnormalities and excitotoxicity in Huntington's disease brain. Ann Neurol

63 Tabrizi SJ, Mangiarini L, Workman J, et al. Mitochondrial biochemical features of the

64 Lisease. Ann Neurol 2000;47:80-6. Abnormal in vivo skeletal muscle energy
metabolism in Huntington's disease and 
dentatorubropallidoluysian atrophy. Ann

65 Ferrante RJ, Andreassen OA, Jenkins BG, et al. Neuroprotective effects of creatine in a Irransgenic mouse model of Huntington's
disease. I Neurosci 2000;20:4389-97.

66 Schaefer M, Hopkins RG, Failla M, et al. copper-dependent trafficking of the Wilson's disease protein in the

67 Lutsenko S, Cooper M. Localization of the Wilson's disease protein product to
mitochondria. Proc Natl acad Sci USA 1998;95:6004-9;

68 Gu M, Cooper JM, Butler P, et al. Oxidative-phosphorylation defects in liver of patients with Wilson's
2000; 356:469-74

69 Polymeropoulos $\mathrm{MH}$, Lavedan C, Leroy $\mathrm{E}$, al. Mutation in the a-synuclein gene identified in families with Parkinson's disease. Science

1997; 276:2045-7.
70 Krüger R, Kuhn W, Muller T, et al. Ala30Pro mutation in the gene a-synuclein in Parkinso

71 Kitada T, Asakawa S, Hattori N, et al Mutations in the parkin gene cause autosomal recessive juvenile parkinsonism. Nature
1998:392:605-8. 1998;392:605-8.

72 Leroy E, Boyer R, Auburger $G$, et al. The ubiquitin pathway in Parkin
Nature 1998;395:451-2.

73 Betarbet K, Sherer TB, MacKenzie G, et al. Chronic systemic pesticide reproduces features of Parkinson's disease. Nat Neurosci

74 Schapira AHV, Gu M, Taanman J-W, et al. Mitochondria in the aetiology and pathogenesis of Parkinson's disease. Ann 75 Neurol 1998;44; (suppl 1):S89-98.

Abnormalities of the electron transport chain in idiopathic Parkinson's disease. Ann Neuro

76 Swerdlow RH, Parks JK, Miller SW, et al. Origin and functional consequences of the Neurol 1996;40:663-71.

77 Gu M, Cooper JM, Taanman JW, et al. Mitochondrial DNA Iransmission of the mitochondrial defect in Parkinson's disea

Kish SJ, Bergeron C, Rajput A

cytochrome oxidase in Alzheimer's disease. Neurochem 1992;59:776-9

79 Parker WD, Parks J, Filley CM, et al. Electron transport chain defects in Alzheimer's diseas Parker WD Parks JK Cytoch

in Alzaridase characterization. Neurology 1995:45:482-6.

81 Parker WD, Filley CM, Parks JK. Cytochrom oxidase deficiency in Alzheimer's

82 Chandrasekaran K, Hatanpaa K, Rapoport Chandrasekaran K, Hatanpaa K, Rapopor mitochondrial DNA encoded genes of oxidalive phosphorylation in association 1997;44;99-104.

83 Davis RE, Miller S, Herrnstadt $C$, et al. Mutations in mitochondrial cytochrome $c$ oxidase genes segregate with late-onset
Alzheimer disease. Proc Natl Acad Sci USA 1997:94:4526-31.

84 Hirano M, Shtilbans A, Mayeux R, et al. Apparent m+DNA heteroplasmy in Alzheimer's disease patients and in normals due to PCR amplification of nucleus-embedded mtDNA pseudogenes. Proc

85 Wallace DC, Stugard C, Murdock D, et al. Ancient mtDNA sequences in the human in identifying pathogenic mutations. Proc Natl Acad Sci USA 1997; 94: 14900-5.

86 Wong-Riley MTT. Cytochrome oxidase: an endogenous metabolic marker for neuronal

87 Kish SJ, Mastrogiacomo F, Guttman H, et al. Decreased brain protein levels of cytochrom oxidase subunits in Alzheimer's disease and in hereditary spinocerebellar ataxia disorders:

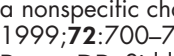

88 Rosen DR, Siddique T, Patterson D, et al. Mutations in $\mathrm{Cu} / \mathrm{Zn}$ superoxide dismutase gene are associated with familial amyotrophic 89 Wiedau-Pazos M Goto JJ, Rabizadeh S, et Wiedau-Pazos $M$, Goto JJ, Rabizadeh $S$, ef
al. Altered reactivity of superoxide dismutase in familial amyotrophic lateral sclerosis. Science 1996;271:515-18.

90 Bowling AC, Schulz JB, Brown RH, et al. Superoxide dismutase activity, oxidative damage amd mitochondrial energy
metabolism in familial and sporadic metabolism in familial and sporadic
amyotrophic lateral sclerosis. I Neuroche 1993;61:2322-5.

91 Shaw $P J$, Ince $P G$, Falkous $G$, et al. motor neuron disease spinal cord. Ann Neurol
matic

92 Abe K, Pan LH, Watanabe $M$, et al. Induction of nitrotyrosine-like imminoreactivity in the

sclerosis. Neurosci Lett 1995;199:152-4.

3 Beal MF, Ferrante RJ, Browne SE, et al. Increased 3-nitrotyrosine in both sporadic and familial amyotrophic latera

94 Ferrante RJ, Browne SE, Shinobu LA, et al. Evidence of increased oxidative damage in both sporadic and familial amyotrophic lateral sclerosis. J Neurochem 1997;69:2064-74.

5 Pedersen WA, Fu WM, Keller JN, et al. Protein modification by lipid peroxidation
product 4-hydroxynonenal in the spinal cords
of amyotrophic lateral sclerosis patients. Ann Neurol 1998;44:819-24.

96 Bogdanov M, Brown RH, Matson W, et al. Increased oxidative damage to DNA in ALS patients. Free Radic
2000;29:652-8.
97 Andrus PK, Fleck TJ, Gurney ME, et al. Protein oxidative damage in a transgenic sclerosis. I Neurochem 1998:71:2041-8.

98 Aguirre T van den Bosch L, Goetschalkx K, Aguirre $T$, Inan den Bosch L, Goetschalckx $\mathrm{K}$ amyotrophic lateal sclerosis patients to
oxidative stress. Ann Neurol 1998;43:452-7.

99 Browne SE, Bowling AC, Baik M, et at. Metabolic dysfunction in familial, but no sproadic, amyotrophic lateral sclerosis.

00 Wiedemann FR Winkler K Ku al. Impairment of mitochondrial function in, skeletal muscle of patients with amyotrophic ateral sclerosis. J Neurol Sci

101 Vielhaber S, Winkler K, Kirsches E, et al. Visualization of defective mitochondrial with sporadic amyotrophic lateral sclerosis. Neurol Sci 1999;169:133-9.

102 Vielhaber S, Kunz D, Winkler K, et al. Mitochondrial DNA abnormalities in skeletal muscle of patients with sporadic amyotrophic

03 Sasaki S, Iwata M. Ultrastructural study of sasaki S, Iwata M. Ulirastructural study of patients with amyotrophic lateral sclerosis. Neurosci Lett 1996;204:53-6.

104 Kong J, Xu Z. Massive mitochondrial degeneration in motor neurons triggers the onset of amyotrophic lateral sclerosis in mice expressing a mutant

105 Wong PC, Pardo CA, Borchelt DR et al An adverse property of a familial ALS-linked SOD 1 mutation causes motor neuron disease characterized by vacuolar degeneration of
mitochondria. Neuron 1995;14:1 105-16.

mitochondria. Neuron 1995; 14:1105-16.
106 Borthwick GM, Johnson MA, Ince PG, et al. Mitochondrial enzyme activity in amyotrophic mitochondria in neuronal cell death. Ann Neurol 1999:46:787-90.

107 Dhaliwal GK, Grewal RP. Mitochondrial DNA deletion mutation levels are elevated in 18 ALS brains. Neuroreport 2000;1 1:2507-9.

8 Bruijn LI, Beal MF, Becher MW, et al. Elevated free nitrotyrosine levels, but no radicals, throughout amyotrophic lateral sclerosis (ALS)-like disease implicate tyrosine nitration as an aberrant in vivo property of one familial ALS-linked superoxide dismutas 1 mutant. Proc Natl Acad Sci USA

109 Ferrante RJ, Shinobu LA, Schulz JB, et al. Increased 3-nitrotyrosine and oxidative superoxide dismutase mutation. Ann Neuro 1997;42:326-34.

110 Klivenyi P, Ferrante RJ, Matthews RT, et al. Neuroprotective effects of creatine in a ransgenic animal model of amyotrophic 